\title{
Lifestyle risk factors of stroke in young Indians
}

\author{
Deeraj Kumar ${ }^{1, *}$, Rajendra Pal Singh², AK Hooda ${ }^{3}$, BS Deswal ${ }^{4}$, KM Hassan ${ }^{5}$
}

${ }^{1}$ Internist, ${ }^{2}$ Community Medicine Specialist, Indian Field Hospital Level II Plus, United Nations Mission in South Sudan, South Sudan, ${ }^{3}$ Nephrologist, Ministry of Defence, ${ }^{4}$ Professor \& Head, SGT Medical College, Gurugram, Haryana, ${ }^{5}$ Senior Consultant Neurologist, Yatharth Super Speciality Hospital, Noida, Uttar Pradesh, India

*Corresponding Author:

Email: dheerajkumar29@yahoo.com

\begin{abstract}
Introduction: Stroke is a leading cause of death and claims 6 million lives every year worldwide. Etiology of stroke is extremely diverse in the young, risk factors differ considerably in young adults compared to those in older individuals. Lifestyle related risk factors play significant role in causation of stroke. The most frequent modifiable lifestyle related risk factors are smoking, physical inactivity, arterial hypertension, diabetes, dyslipidemia, and obesity. Prevention of stroke in the young assumes paramount importance as it increases number of quality-adjusted life years (QALY) much more in young than in elderly population.

Objectives: To study the different lifestyle related risk factors in patients of stroke in age group 15-49 years.

Materials and Methods: Patients of stroke between ages 15-49 years, who reported to Outpatient Neurology Services or admitted to a tertiary care service hospital, were evaluated for various potential lifestyle related risk factors which were analysed in detail using SPSS 15.0.

Results: Out of total 144 cases studied alcohol consumption was found in 70 (48.6\%) cases, smoking was present in 36 (25\%) cases, while $50(34.7 \%)$ cases were hypertensive, $10(6.9 \%)$ cases were diabetic, $15(10.4 \%)$ were obese and dyslipidemia was found in $56(38.8 \%)$; multiple risk factors were found in $22(15.3 \%)$ cases.

Conclusion: Amongst lifestyle related problems alcohol, smoking, hypertension, diabetes and dyslipidemia followed by obesity were important risk factors for strokes in young. Unhealthy life style not only leads to increased chances of stroke, but also carries higher all cause mortality after stroke. The need of immediate vigorous primary and secondary preventive measures targeting the lifestyle modifications and risk factor among young population in developing countries in inevitable.
\end{abstract}

Keywords: Stroke, Young, Lifestyle risk factors.

\section{Introduction}

Stroke is defined by world health organisation (WHO) as an event caused by the interruption of the blood supply to the brain, usually because a blood vessel bursts or is blocked by a clot. This cuts off the supply of oxygen and nutrients, causing damage to the brain tissue. ${ }^{1}$ Stroke is a leading cause of death and claims 6 million lives every year worldwide. ${ }^{2}$ According to WHO, Stroke and Ischaemic heart disease accounted for a combined 15 million deaths in 2015, more than two third occurring in less developed countries. $^{3}$ More than $4 \%$ of direct health care expenditure in developed countries is incurred on stroke. ${ }^{2}$ Though being one of the leading causes of disability and death worldwide, it gains even more importance because of increasing propensity to affect young people. Up to $10-20 \%$ of ischaemic strokes have been reported to occur in young individuals. ${ }^{4}$ In India, during the last decade, the crude prevalence rates of stroke was between 136 and 220 per $1,00,000$ population. ${ }^{5-8}$ It is emphasised that developing countries are facing the main brunt of this disease because of increasing prevalence of hypertension, fast-changing lifestyle and population restructuring. ${ }^{9}$

Etiology of stroke is extremely diverse in the young, risk factors differ considerably in young adults compared to those in older individuals. Lifestyle related risk factors play significant role in causation of stroke.
The most frequent lifestyle related modifiable risk factors are smoking, physical inactivity, arterial hypertension, diabetes, dyslipidemia, and obesity. Besides, alcohol in men and migraine in women are important modifiable risk factors for stroke in young. ${ }^{10}$

Stroke in young causes marked long term socioeconomic consequences and has a high public health impact due to associated indirect cost as the young stroke patients are at their most productive age. Prevention of stroke in the young assumes paramount importance as it increases number of quality-weighted life years much more in young than in elderly population. However, despite being so important, stroke in the young has long been understudied and currently available data is still derived mostly from developed countries and from small patient series. ${ }^{11-13}$ There is very little knowledge available about preventive impact of low risk lifestyle in the occurrence of disease. ${ }^{14} \mathrm{~A}$ large European cohort of 18 to 55 years patients with acute ischaemic stroke or Transient ischaemic attacks has high prevalence of modifiable risk factors. ${ }^{10}$ In a study by Lee et al, vascular risk factors like hypertension, diabetes mellitus, dyslipidemia were seen more commonly in patients with large artery atherosclerotic disease and small vessel occlusive disease. ${ }^{15}$ The beneficial impact of low risk lifestyle on prevention of stroke has already been established in Nurses Health Study. ${ }^{16}$ 
In the light of available literature, it is emphasised that risk factors, particularly related to life style, needs to be studied in detail, stratified and primordial and primary preventive strategies need to be re-evaluated to curb the menace of lifestyle related cerebrovascular events which are definitely preventable.

\section{Objectives}

To study the different lifestyle related risk factors in patients of stroke in age group 15-49 years.

\section{Materials and Methods}

1. Study design: Prospective observational study

2. Study population: Patients of stroke between ages 15-49 years, who reported to Outpatient Neurology Services or admitted to a tertiary care service hospital in a metropolitan city in Eastern India.

3. Sample size: The proposed sample size to be studied was based on average incidence of $16 \%$ of stroke in young adults in India ${ }^{17}$ Considering alpha error of $5 \%$ and error value of $8 \%$ on either side, a sample size of 81 was computed. It was proposed to study 100 patients of young stroke meeting eligibility criteria mentioned below. However, 144 patients presented to study hospital during 31 May 2010 to 30 June 2013 were included in the study. While all the patients were treated for stroke as per standard protocol, the detailed examination and investigations revealed various potential modifiable and non-modifiable risk factors which were analysed in detail.

4. Study period: 31 May 2010 to 30 June 2013

5. Inclusion criteria: Patients with first ever stroke (ischemic/ hemorrhagic/cerebral venous thrombosis) in age group 15-49 years.

6. Exclusion criteria: Stroke patients $<15$ years and $>49$ years of age, recurrent strokes, and Transient Ischemic Attack (TIA)

7. Study protocol: All cases diagnosed as Stroke during the study period at the hospital, underwent detailed history taking, clinical examination, basic and specific investigations. While all the patients were treated for stroke as per standard protocol, the detailed history recorded on a structured Proforma, examination and investigations revealed various potential modifiable and non-modifiable risk factors which were analysed in detail.

8. Analysis of data: All raw data collected on proforma entered into a Microsoft Excel Spreadsheet and analysed using standard statistical software, Statistical Programme for Social Sciences (SPSS) 15.0 for Microsoft Windows (SPSS Inc. Chicago, IL, USA), Continuous numerical data was described as means, standard deviations, medians, minimum, maximum and standard error of mean. Further, mean was compared across 3 groups by ANNOVA test, distributions were compared using Pearson's Chi
Square Test. Two-sided values of $\mathrm{P}<0.05$ were considered statistically significant.

9. Parameters studied: Following lifestyle related risk factors in a patient of stroke in age group 1549 years were studied:-

a. Alcohol: Alcohol consumption was taken as significant when an individual consumed more than $70 \mathrm{gm}$ of alcohol in females and $140 \mathrm{gm}$ in males per week. ${ }^{18}$

b. Smoking: Smoker was defined as an individual who had smoked greater than 100 cigarettes in their life time and currently smoking prior to event. $^{19}$

c. Blood pressure: Upper level of normal blood pressure was taken as $140 / 90 \mathrm{~mm}$ of $\mathrm{Hg}^{20}$

d. Obesity: As per WHO BMI greater than or equal to $30 . .^{21}$

e. Diabetes: As per WHO definition Fasting Blood sugar level >126 mg/dl, RBS > $200 \mathrm{mg} / \mathrm{dl}$ in presence of osmotic symptoms. ${ }^{22}$

f. Dyslipidemia: Serum Cholesterol $>200 \mathrm{mg} / \mathrm{dl}$, LDL > 100mg/dl, Triglycerides > 150mg/dl..$^{21}$

g. Haemoglobin level: Anaemia: $<12.0 \mathrm{~g} / \mathrm{dL}$ in women and $<13.0 \mathrm{~g} / \mathrm{dL}$ in men and Polycythemia. $^{23,24}$

10. Study format: Patient's name, address, other personal details were noted and detailed history taking and examination were done at initial presentation Baseline investigations like hemoglobin level $(\mathrm{Hb})$, total leukocyte count (TLC), lipid profile, random blood sugar level (RBS), platelets, prothrombin time (PT), international normalized ratio (INR), chest $\mathrm{X}$ ray, electrocardiogram (ECG) were done in all patients and specific investigations were carried out on basis of initial presentation and findings of baseline investigations.

\section{Results}

\section{Stroke types and subtypes}

In our study, out of 144 patients included in study, $99(68.7 \%)$ patients were of ischemic strokes, 19 $(13.2 \%)$ patients were of hemorrhagic strokes and 26 (18.1\%) patients were of cerebral venous thrombosis (CVT).(Fig. 1)

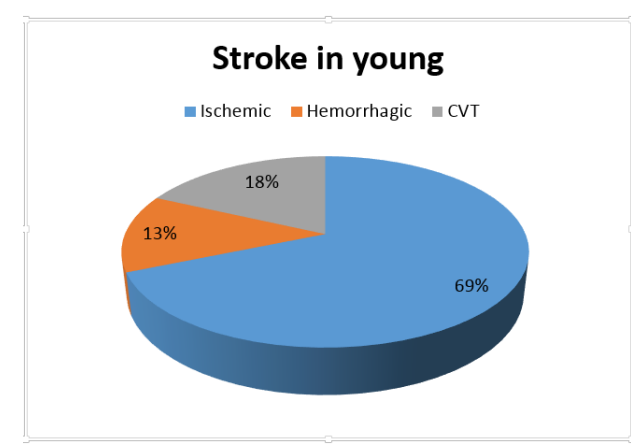

Fig 1: Distribution of Stroke in Young 
Sex: Hemorrhagic stroke was seen in $26.3 \%$ females whereas $7.1 \%$ females were in ischemic stroke group and $3.8 \%$ females were in CVT group. (Fig. 2)

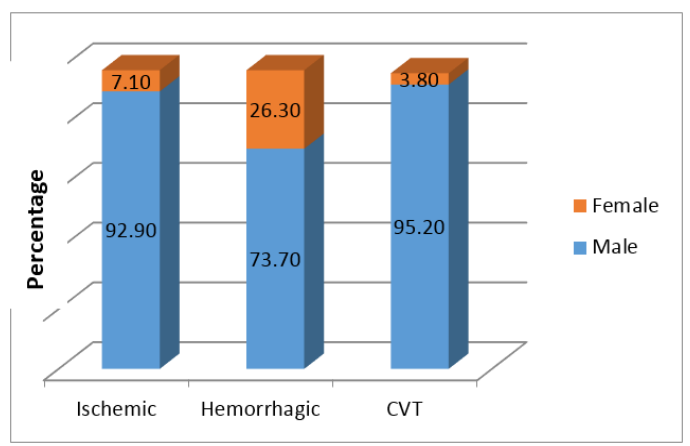

Fig. 2: Distribution of Strokes in Different Sexes

\section{Risk factors}

Alcohol consumption was found in 70 (48.6\%) cases, smoking was present in $36(25 \%)$ cases, while 50 $(34.7 \%)$ cases were hypertensive, $10(6.9 \%)$ cases were diabetic, $15(10.4 \%)$ were obese and dyslipidemia was found in $56(38.8 \%)$; multiple risk factors were found in $22(15.3 \%)$ cases. (Fig. 3)
Alcohol consumption was found in $11(42.3 \%)$ cases of CVT, 10 (52.6\%) cases of hemorrhagic strokes and 49 $(49.5 \%)$ cases of ischemic strokes. (Fig. 4)

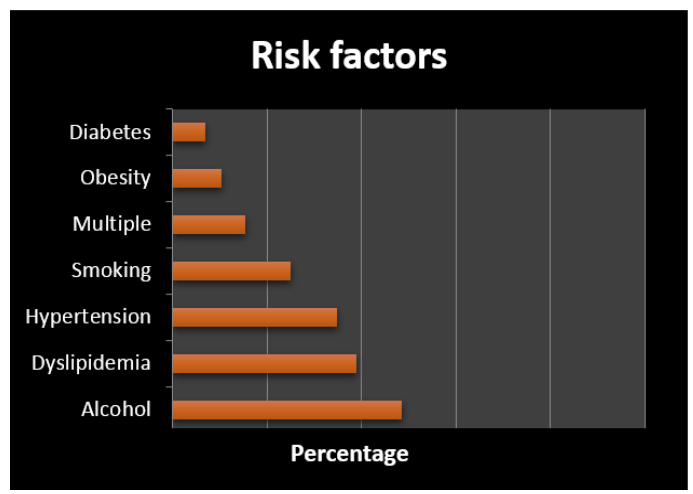

Fig. 3: Distribution of Modifiable Risk Factors Observed among Study Subjects

Smoking was found in $2(7.7 \%)$ cases of CVT, 3 $(15.8 \%)$ cases of hemorrhagic strokes and 31 (31.3\%) cases of ischemic strokes. However it was not an important risk factor in respect of any type of stroke whether CVT, hemorrhagic or ischemic strokes ( $\mathrm{p}$ value $>0.555)$ (Table 1) (Fig. 4).

Table 1: Smoking as a risk factor in different types of stroke

\begin{tabular}{|l|l|c|c|c|}
\hline & & \multicolumn{2}{c|}{ Smoking } & Total \\
\hline & \multicolumn{1}{|c|}{ CVT } & Present & Absent & \\
\hline Group & Hemorrhagic strokes & 3 & 16 & 26 \\
\hline & Ischemic strokes & 31 & 68 & 19 \\
\hline & Total & 36 & 108 & 144 \\
\hline $\begin{array}{c}\text { Statistical test } \\
\text { used }\end{array}$ & Value & \multicolumn{2}{|l|}{ Degree of freedom } & $\begin{array}{c}\text { Significance } \\
\text { (2-sided) }\end{array}$ \\
\hline Pearson Chi-Square & 36.147 & \multicolumn{2}{|c|}{38} & .555 \\
\hline Likelihood Ratio & 39.890 & \multicolumn{2}{|l}{38} & .386 \\
\hline N of Valid Cases & 144 & \multicolumn{3}{l}{} \\
\hline
\end{tabular}

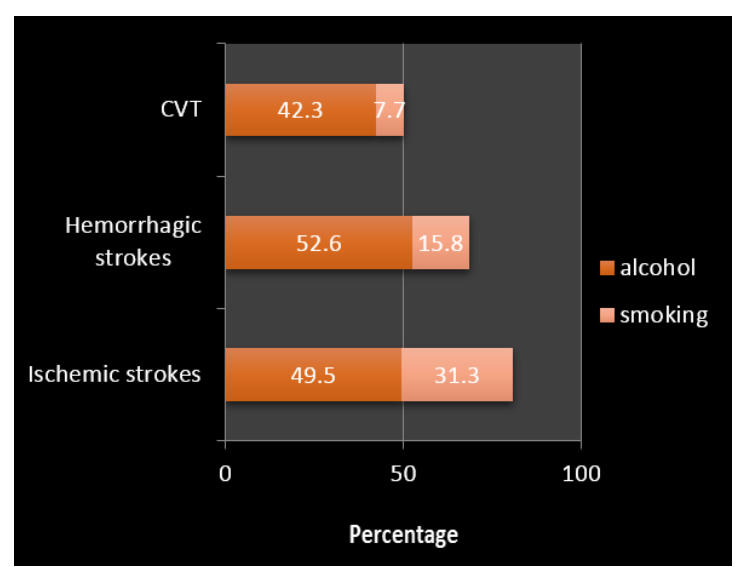

Fig. 4: Alcohol and Smoking in Stroke

Hypertension was present in $12(63.2 \%)$ cases of hemorrhagic strokes, 38 (38.4\%) cases of ischemic strokes, whereas none was hypertensive in case of CVT. Past history of hypertension was not found in 7 (36.8\%) cases of hemorrhagic strokes amongst whom $4(21.1 \%)$ cases were alcoholic, $2(10.5 \%)$ cases had subarachnoid hemorrhage 
and one (5.2\%) had tumor bleed (choriocarcinoma). One (5.2\%) patient had multiple risk factors. Hypertension was statistically significant as a risk factor in cases of hemorrhagic strokes and ischemic strokes as compare to CVT (p value $<0.001$ (Table 2)

Table 2: Hypertension in stroke

\begin{tabular}{|c|c|c|c|c|c|c|c|c|}
\hline \multicolumn{5}{|c|}{ Strokes } & \multirow{2}{*}{ Total } & \multirow{2}{*}{$\begin{array}{c}\text { P Value between } \\
\text { Ischemic \& } \\
\text { Haemorrhagic } \\
\text { strokes }\end{array}$} & \multirow{2}{*}{\begin{tabular}{|c|} 
P Value \\
between CVT \\
\& Ischemic \\
strokes
\end{tabular}} & \multirow{2}{*}{$\begin{array}{c}\text { P Value between } \\
\text { CVT \& } \\
\text { Haemorrhagic } \\
\text { strokes } \\
\end{array}$} \\
\hline & & Ischemic & Hemorrhagic & CVT & & & & \\
\hline \multirow{4}{*}{ HTN } & & 61 & 7 & 26 & 94 & \multirow{4}{*}{0.045} & \multirow{4}{*}{$<0.001$} & \multirow{4}{*}{$<0.001$} \\
\hline & No & $61.6 \%$ & $36.8 \%$ & $100.0 \%$ & $65.3 \%$ & & & \\
\hline & \multirow{2}{*}{ Yes } & 38 & 12 & 0 & 50 & & & \\
\hline & & $38.4 \%$ & $63.2 \%$ & $.0 \%$ & $34.7 \%$ & & & \\
\hline \multirow{2}{*}{\multicolumn{2}{|c|}{ Total }} & 99 & 19 & 26 & 144 & & & \\
\hline & & $100.0 \%$ & $100.0 \%$ & $100.0 \%$ & $100.0 \%$ & & & \\
\hline
\end{tabular}

Diabetes was present in $10(10.1 \%)$ cases of ischemic strokes, none was found diabetic in cases of CVT and hemorrhagic strokes. However it is not statistically significant when compared with CVT and hemorrhagic strokes (p values 0.091 and 0.148 respectively). (Table 3 )

Table 3: Diabetes mellitus in ischaemic stroke, haemorrhagic stroke and DVT

\begin{tabular}{|c|c|c|c|c|c|}
\hline & & \multicolumn{3}{|c|}{ Strokes } & \multirow{2}{*}{ Total } \\
\hline & & Ischemic & Hemorrhagic & CVT & \\
\hline \multirow{3}{*}{ DM } & \multirow{2}{*}{ No } & 89 & 19 & 26 & 134 \\
\cline { 3 - 6 } & & $89.9 \%$ & $100.0 \%$ & $100.0 \%$ & $93.1 \%$ \\
\cline { 3 - 6 } & \multirow{2}{*}{ Yes } & 10 & 0 & 0 & 10 \\
\cline { 3 - 6 } & $10.1 \%$ & $.0 \%$ & $.0 \%$ & $6.9 \%$ \\
\hline \multicolumn{2}{|c|}{ Total } & 99 & 19 & 26 & 144 \\
\cline { 3 - 6 } & $100.0 \%$ & $100.0 \%$ & $100.0 \%$ & $100.0 \%$ \\
\hline
\end{tabular}

Higher values of triglycerides were found in case of CVT $(170.69 \pm 71.73 \mathrm{mg} / \mathrm{dl})$ as compared to ischemic $(140.23 \pm 54.36 \mathrm{mg} / \mathrm{dl})(\mathrm{p}$ value 0.034$)$ and hemorrhagic strokes $(133.37 \pm 54.72 \mathrm{mg} / \mathrm{dl})(\mathrm{p}$ value 0.018$)($ Table1) (Table 3). Higher values of triglycerides were associated more with CVT as compared to ischemic and hemorrhagic groups ( $\mathrm{p}$ value 0.040 ) (Table 3) (Table2). Statistically significant higher values were found in ischemic strokes as compared to hemorrhagic strokes ( $\mathrm{p}$ value 0.018 ) (Table 4).

Table 4: Mean, SD, SE, $95 \%$ confidence interval for risk factors

\begin{tabular}{|c|c|c|c|c|c|c|c|c|c|c|}
\hline & \multirow[t]{2}{*}{$\mathbf{N}$} & \multirow[t]{2}{*}{ Mean } & \multirow[t]{2}{*}{ SD } & \multicolumn{2}{|c|}{$\begin{array}{c}95 \% \\
\text { Confidence } \\
\text { Interval for } \\
\text { Mean }\end{array}$} & \multirow[t]{2}{*}{ Min } & \multirow[t]{2}{*}{ Max } & \multirow[b]{2}{*}{$\begin{array}{c}\mathbf{F} \\
\text { statistic }\end{array}$} & \multirow[b]{2}{*}{$\begin{array}{c}\mathbf{p} \\
\text { value }\end{array}$} \\
\hline & & & & & $\begin{array}{l}\text { Lower } \\
\text { Bound }\end{array}$ & $\begin{array}{l}\text { Upper } \\
\text { Bound }\end{array}$ & & & & \\
\hline \multirow[t]{3}{*}{ Age } & CVT & 26 & 32.54 & 7.112 & 29.67 & 35.41 & 22 & 45 & & \\
\hline & Hemorrhagic & 19 & 41.00 & 6.725 & 37.76 & 44.24 & 24 & 48 & 14.792 & .000 \\
\hline & Ischemic & 99 & 40.08 & 6.382 & 38.81 & 41.35 & 22 & 49 & & \\
\hline \multirow{3}{*}{$\begin{array}{l}\mathrm{Hb} \\
(\mathrm{gm} / \mathrm{dl})\end{array}$} & CVT & 26 & 14.254 & 1.6226 & 13.598 & 14.909 & 8.4 & 17.0 & & \\
\hline & Hemorrhagic & 19 & 12.863 & 1.9394 & 11.928 & 13.798 & 8.2 & 16.0 & 3.428 & .035 \\
\hline & Ischemic & 99 & 13.743 & 1.7697 & 13.390 & 14.096 & 8.0 & 18.2 & & \\
\hline \multirow{3}{*}{$\begin{array}{l}\text { CHOL } \\
(\mathrm{mg} / \mathrm{dl})\end{array}$} & CVT & 26 & 183.96 & 71.733 & 154.99 & 212.94 & 132 & 481 & & \\
\hline & Hemorrhagic & 19 & 164.16 & 37.993 & 145.85 & 182.47 & 109 & 285 & 1.414 & .246 \\
\hline & Ischemic & 99 & 168.23 & 38.287 & 160.60 & 175.87 & 72 & 280 & & \\
\hline \multirow{2}{*}{$\begin{array}{l}\text { TG } \\
(\mathrm{mg} / \mathrm{dl})\end{array}$} & CVT & 26 & 170.69 & 71.768 & 141.70 & 199.68 & 85 & 435 & & \\
\hline & Hemorrhagic & 19 & 133.37 & 54.722 & 106.99 & 159.74 & 53 & 279 & 3.281 & .040 \\
\hline
\end{tabular}




\begin{tabular}{|l|l|c|c|c|c|c|c|c|c|c|}
\hline & Ischemic & 99 & 140.23 & 54.356 & 129.39 & 151.07 & 48 & 345 & & \\
\hline \multirow{2}{*}{$\begin{array}{l}\text { HDL } \\
(\mathrm{mg} / \mathrm{dl})\end{array}$} & CVT & 26 & 43.15 & 13.266 & 37.80 & 48.51 & 30 & 100 & & \\
\cline { 2 - 12 } & Hemorrhagic & 19 & 42.47 & 5.274 & 39.93 & 45.02 & 38 & 60 & 1.528 & .221 \\
\cline { 2 - 12 } & Ischemic & 99 & 40.34 & 6.718 & 39.00 & 41.68 & 20 & 68 & & \\
\hline \multirow{2}{*}{$\begin{array}{l}\text { LDL } \\
(\mathrm{mg} / \mathrm{dl})\end{array}$} & CVT & 26 & 110.77 & 52.582 & 89.53 & 132.01 & 45 & 306 & & \\
\cline { 2 - 11 } & Hemorrhagic & 19 & 97.32 & 27.968 & 83.84 & 110.80 & 48 & 168 & 1.040 & .356 \\
\cline { 2 - 11 } & Ischemic & 99 & 99.56 & 34.347 & 92.71 & 106.41 & 22 & 195 & & \\
\hline
\end{tabular}

Cholesterol levels were higher in case of CVT with mean value of $183.96 \pm 71.3 \mathrm{mg} / \mathrm{dl}$ as compared to ischemic strokes (mean value $168.23 \pm 38.2 \mathrm{mg} / \mathrm{dl}$ ) and hemorrhagic strokes (mean value $164.16 \pm 37.9 \mathrm{mg} / \mathrm{dl}$ ), however these were not statistically significant (p value 0.246) (Table 5) (Table 2). Similarly, differences in HDL and LDL levels amongst different types of strokes were not statistically significant ( $p$ values 0.221 and 0.356 respectively) (Table 4)

Lower level of hemoglobin was found in cases of hemorrhagic strokes with mean $\mathrm{Hb}$ level being $12.8 \pm 1.92$

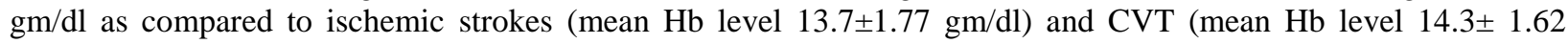
$\mathrm{gm} / \mathrm{dl}$ ). Lower values are associated with hemorrhagic strokes ( $\mathrm{p}$ value 0.010). Also higher values of $\mathrm{Hb}$ are associated with CVT as compared to ischemic strokes (p value0.035). (Tables 4,5) There were 6 cases of migraine observed in our study.

Table 5: Multiple Comparisons

\begin{tabular}{|c|c|c|c|c|c|c|c|}
\hline \multirow[t]{2}{*}{$\begin{array}{c}\text { Dependent } \\
\text { Variable }\end{array}$} & \multirow[t]{2}{*}{$\begin{array}{l}\text { (I) } \\
\text { group } \\
\text { cat }\end{array}$} & \multirow[t]{2}{*}{$\begin{array}{l}\text { (J) group } \\
\text { cat }\end{array}$} & \multirow[t]{2}{*}{$\begin{array}{c}\text { Mean } \\
\text { Difference } \\
(\mathbf{I}-\mathbf{J})\end{array}$} & \multirow[t]{2}{*}{$\begin{array}{l}\text { Std. } \\
\text { Error }\end{array}$} & \multirow[t]{2}{*}{ Sig. } & \multicolumn{2}{|c|}{$\begin{array}{c}95 \% \\
\text { Confidence } \\
\text { Interval }\end{array}$} \\
\hline & & & & & & $\begin{array}{l}\text { Lower } \\
\text { Bound }\end{array}$ & $\begin{array}{l}\text { Upper } \\
\text { Bound }\end{array}$ \\
\hline \multirow[t]{6}{*}{ Age } & \multirow[t]{2}{*}{1.00} & hemorrhagic & $-8.462^{*}$ & 1.980 & .000 & -12.38 & -4.55 \\
\hline & & ischemic & $-7.542^{*}$ & 1.446 & .000 & -10.40 & -4.68 \\
\hline & \multirow[t]{2}{*}{2.00} & CVT & $8.462^{*}$ & 1.980 & .000 & 4.55 & 12.38 \\
\hline & & ischemic & .919 & 1.643 & .577 & -2.33 & 4.17 \\
\hline & \multirow[t]{2}{*}{3.00} & CVT & $7.542^{*}$ & 1.446 & .000 & 4.68 & 10.40 \\
\hline & & hemorrhagic & -.919 & 1.643 & .577 & -4.17 & 2.33 \\
\hline \multirow[t]{6}{*}{$\mathrm{Hb}(\mathrm{gm} / \mathrm{dl})$} & \multirow[t]{2}{*}{1.00} & hemorrhagic & $1.3907^{*}$ & .5334 & .010 & .336 & 2.445 \\
\hline & & ischemic & .5104 & .3895 & .192 & -.260 & 1.280 \\
\hline & \multirow[t]{2}{*}{2.00} & CVT & $-1.3907^{*}$ & .5334 & .010 & -2.445 & -.336 \\
\hline & & ischemic & $-.8803^{*}$ & .4427 & .049 & -1.755 & -.005 \\
\hline & \multirow[t]{2}{*}{3.00} & CVT & -.5104 & .3895 & .192 & -1.280 & .260 \\
\hline & & hemorrhagic & $.8803^{*}$ & .4427 & .049 & .005 & 1.755 \\
\hline \multirow[t]{6}{*}{$\mathrm{CHOL}(\mathrm{mg} / \mathrm{dl})$} & \multirow[t]{2}{*}{1.00} & Hemorrhagic & 19.804 & 13.882 & .156 & -7.64 & 47.25 \\
\hline & & ischemic & 15.729 & 10.136 & .123 & -4.31 & 35.77 \\
\hline & \multirow[t]{2}{*}{2.00} & CVT & -19.804 & 13.882 & .156 & -47.25 & 7.64 \\
\hline & & ischemic & -4.074 & 11.520 & .724 & -26.85 & 18.70 \\
\hline & \multirow[t]{2}{*}{3.00} & CVT & -15.729 & 10.136 & .123 & -35.77 & 4.31 \\
\hline & & hemorrhagic & 4.074 & 11.520 & .724 & -18.70 & 26.85 \\
\hline \multirow[t]{6}{*}{$\mathrm{TG}(\mathrm{mg} / \mathrm{dl})$} & \multirow[t]{2}{*}{1.00} & hemorrhagic & $37.324^{*}$ & 17.466 & .034 & 2.79 & 71.85 \\
\hline & & ischemic & $30.460^{*}$ & 12.753 & .018 & 5.25 & 55.67 \\
\hline & \multirow[t]{2}{*}{2.00} & CVT & $-37.324^{*}$ & 17.466 & .034 & -71.85 & -2.79 \\
\hline & & ischemic & -6.864 & 14.495 & .637 & -35.52 & 21.79 \\
\hline & \multirow[t]{2}{*}{3.00} & CVT & $-30.460^{*}$ & 12.753 & .018 & -55.67 & -5.25 \\
\hline & & hemorrhagic & 6.864 & 14.495 & .637 & -21.79 & 35.52 \\
\hline \multirow[t]{6}{*}{$\mathrm{HDL}(\mathrm{mg} / \mathrm{dl})$} & \multirow[t]{2}{*}{1.00} & hemorrhagic & .680 & 2.454 & .782 & -4.17 & 5.53 \\
\hline & & Ischemic & 2.810 & 1.792 & .119 & -.73 & 6.35 \\
\hline & \multirow[t]{2}{*}{2.00} & CVT & -.680 & 2.454 & .782 & -5.53 & 4.17 \\
\hline & & ischemic & 2.130 & 2.037 & .297 & -1.90 & 6.16 \\
\hline & \multirow[t]{2}{*}{3.00} & CVT & -2.810 & 1.792 & .119 & -6.35 & .73 \\
\hline & & hemorrhagic & -2.130 & 2.037 & .297 & -6.16 & 1.90 \\
\hline \multirow[t]{2}{*}{$\mathrm{LDL}(\mathrm{mg} / \mathrm{dl})$} & 1.00 & hemorrhagic & 13.453 & 11.333 & .237 & -8.95 & 35.86 \\
\hline & & ischemic & 11.214 & 8.275 & .178 & -5.15 & 27.57 \\
\hline
\end{tabular}




\begin{tabular}{|l|c|l|c|c|c|c|c|}
\hline \multirow{3}{*}{2.00} & CVT & -13.453 & 11.333 & .237 & -35.86 & 8.95 \\
\cline { 3 - 7 } & & ischemic & -2.240 & 9.405 & .812 & -20.83 & 16.35 \\
\cline { 2 - 7 } & \multirow{2}{*}{3.00} & CVT & -11.214 & 8.275 & .178 & -27.57 & 5.15 \\
\cline { 2 - 7 } & & hemorrhagic & 2.240 & 9.405 & .812 & -16.35 & 20.83 \\
\hline
\end{tabular}

\section{Discussion}

This study had higher ratio of male:female (10:1) as compared to previous study done by Putaala et $\mathrm{al},{ }^{4}$ which showed a male: female ratio of $1.7: 1$ and a ratio of 1.8:1 in another study by Razzaq et al. ${ }^{16}$ There were higher proportion of females in hemorrhagic group as compared to ischemic stroke group and CVT. This study also found that CVT was more prevalent in younger age group as compared to ischemic and hemorrhagic strokes in young.

In this study, highest incidence of ischemic strokes (69\%) was found as compared to hemorrhagic strokes (13.2\%) and CVT (18.1\%), which is corroborated by previous studies from Asia and other parts of the world. ${ }^{4,17,25,26,27}$

This study showed that common risk factors in cases of stroke in young were dyslipidemia (38.8\%), hypertension $(34.7 \%)$, followed by multiple risk factors in $15.3 \%$ cases and diabetes was found in $10.4 \%$ cases. In this study, we found alcohol consumption in $48.6 \%$ and smoking in $25 \%$ of strokes in young. Previous studies also showed that alcohol and smoking were important risk factors. ${ }^{15,28,29,30}$ Strong dose response relationship between cigarette smoking and risk of ischemic stroke in young has reinforced the need for aggressive smoking cessation efforts. The risk of having stroke decreases after 3 years of cessation of smoking and reaches to the level of non smokers after 5 years of cessation of smoking. Smoking cessation has immediate and long term health benefits to men and women of all age groups and the life expectancy in a smoker who quits smoking before attaining the age of 35 years is as good as non smokers. ${ }^{31}$

In our study, Hypertension was present in 50 $(34.7 \%)$ cases of stroke in young. Hypertensionwas more prevalent in haemorrhagic stroke $(63.2 \%)$ than ischaemic stroke, none was hypertensive in case of CVT. Hypertension was statistically significant as a risk factor in cases of hemorrhagic strokes and ischemic strokes as compare to CVT ( $\mathrm{p}$ value $<0.001$ ).

The study by Nayak et al showed $42 \%$ cases of stroke had dyslipidemia, $18 \%$ had hypertension and diabetes mellitus was present in $7 \% .{ }^{28}$ Sridharan et al found hypertension, dyslipidemia and diabetes mellitus associated as risk factors with stroke in young

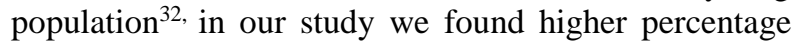
(34.7\% of patients) had hypertension amongst strokes similar to study conducted by Lee et al which showed hypertension in $45.8 \%$ of young strokes. A study from Switzerland found hypercholesterolemia in $39 \%$ and hypertension in $19 \%$ of cases of strokes in young. ${ }^{30}$ Helsinki Young Stroke Registry found multiple causes in 21 patients out of 1008 patients of young strokes. ${ }^{4} \mathrm{~A}$ study from Pakistan showed hypertension in $14 \%$ and miscellaneous causes in $4 \%$ of cases. ${ }^{33}$

Among 4467 patients in Fabry patients study, most frequented modifiable risk factors were smoking (55.5\%), physical inactivity (48.2\%), arterial hypertension $(46.6 \%)$, dyslipidemia $(34.9 \%)$, obesity $922.3 \%$ ) and alcohol consumption $(33 \%)^{10}$ as also in our study we found alcohol(48.6\%), smoking(25\%), dyslipidemia $(38.8 \%$ ) diabetes ( $10.4 \%)$ and multiple risk factors in $15.3 \%$ cases.

In a case control study in South India stroke cases had higher prevalence of smoking (multivariate adjusted Odd's ratio(OR) 7.77, CI 1.93 to 31.27, higher systolic blood pressure (OR per SD increment of 1.88, 95\% CI 1.01 to 3.49], and fasting blood glucose [OR per SD increment of $4.55,95 \%$ CI 1.63 to 12.67], but lower high density lipoprotein (HDL) cholesterol [OR per SD increment of $0.17,95 \% \mathrm{CI} 0.09$ to 0.30 ] when compared with community control. In the same study when compared with hospital control, stroke patients had higher prevalence of smoking [OR 3.95, 95\% CI 1.61 to 9.71], and lower HDL cholesterol [OR per SD increment $0.27,95 \%$ CI 0.17 to 0.44$].{ }^{29}$ In a study on long term prognosis after stroke in Netherland (n 406), smoking $(46.1 \%)$, dyslipidemia (30.8\%), hypertension (25.4\%), diabetes $(4.7 \%)$, and excess drinking (4.9\%) were significant cardiovascular risk factors. ${ }^{2}$ In our study, we found that diabetes is mainly a risk factor for ischemic stroke as supported by previous studies., ${ }^{4}, 15$, ${ }^{32}$ In our study obesity was less $(10.4 \%)$ as against $22.3 \%$ in Fabry study. ${ }^{10}$ Obesity, both general and abdominal is associated with higher risk of stroke, which may be the cause of increased incidence of stroke in women ${ }^{10}$

Dyslipidemia is an important risk factor for stroke in previous studies $4,10,28$, which is also shown in our study. However, in our study we found that high triglyceride and high cholesterol level were associated more with CVT as compare to ischaemic and haemorrhagic group amongst the different types of stroke.

In our study, we observed that anaemia is an important risk factor in hemorrhagic strokes as compared to ischemic strokes and CVT which is in consonance with earlier studies. ${ }^{17}$

Higher values of hemoglobin were associated with CVT as compared to ischemic and hemorrhagic strokes which is corroborated by previous data that found polycythemia as a known risk factor for CVT. ${ }^{34}$

\section{Conclusions}

Amongst lifestyle related problems alcohol, smoking, hypertension, diabetes and dyslipidemia 
followed by obesity were important risk factors for strokes in young. Significant proportions of patients were found to have multiple risk factors. Hypertension and lower levels of hemoglobin were associated with hemorrhagic strokes. Higher levels of hemoglobin were associated with CVT. It is well documented that unhealthy life style not only leads to increased chances of stroke, but also carries higher all cause mortality after stroke. The need of immediate vigorous primary and secondary preventive measures targeting the lifestyle modifications and risk factor among young population in developing countries in inevitable to curb the menace.

\section{References}

1. WHO, "Stroke, Cerebrovascular accident," August 2010, http://www.who.int/topics/cerebrovascular accident.

2. Rutten-Jacobs, L.C.A.Long-term prognosis after stroke in young adults. [dissertation on the internet]. Radboud Universiteit Nijmegen, 14 april 2014. [cited 2017 Dec 25]. Available from http://hdl.handle.net/2066/125600

3. The top 10 causes of death WHO Fact sheet January 2017, available on http://www.who.int/mediacentre/factsheets/fs310/en/, accessed on 24 Dec 2017

4. Putaala J, Metso AJ, Metso TM, Konkola N, Kraemer Y, Haapaniemi E, Kaste M, Tatlisumak T. Analysis of 1008 consecutive patients aged 15 to 49 with first-ever ischemic stroke. Stroke. 2009 Apr 1;40(4):1195-203.

5. Banerjee TK, Das SK. Epidemiology of stroke in India. Neurology Asia. 2006 Jun;11:1-4.

6. Saha SP, Bhattacharya S, Das SK, Maity B, Roy T, Raut DK. Epidemiological study of neurological disorders in a rural population of Eastern India. Journal of the Indian Medical Association. 2003 May;101(5):299-300

7. Banerjee TK, Mukherjee CS, Sarkhel A. Stroke in the urban population of Calcutta-an epidemiological study. Neuro-epidemiology. 2001;20(3):201-7.

8. Gourie-Devi M, Gururaj G, Satishchandra P, Subbakrishna DK. Prevalence of neurological disorders in Bangalore, India: a community-based study with a comparison between urban and rural areas. Neuroepidemiology. 2004;23(6):261-8.

9. Feigin VL, Lawes CM, Bennett DA, Anderson CS. Stroke epidemiology: a review of population-based studies of incidence, prevalence, and case-fatality in the late 20th century. The Lancet Neurology. 2003 Jan $31 ; 2(1): 43-53$.

10. Von Sarnowski B, Putaala J, Grittner U, Gaertner B, Schminke U, Curtze S, Huber R, Tanislav C, Lichy C, Demarin V, Basic-Kes V. Lifestyle risk factors for ischemic stroke and transient ischemic attack in young adults in the Stroke in Young Fabry Patients study. Stroke. 2012 Jan 1:STROKEAHA-112.

11. Berlin L, Tumarkin B, Martin HL. Cerebral thrombosis in young adults. New England Journal of Medicine. 1955 Feb 3;252(5):162-6.

12. Naess H, Nyland HI, Thomassen L, Aarseth J, Nyland G, Myhr KM. Incidence and short-term outcome of cerebral infarction in young adults in western Norway. Stroke. 2002 Aug 1;33(8):2105-8.

13. Ghandehari K, Moud ZI. Incidence and etiology of ischemic stroke in Persian young adults. Acta neurologica scandinavica. 2006 Feb 1;113(2):121-4.

14. Chiuve SE, Rexrode KM, Spiegelman D, Logroscino G, Manson JE, Rimm EB. Primary prevention of stroke by healthy lifestyle. Circulation. 2008 Aug 26;118(9):94754.

15. Lee TH, Hsu WC, Chen CJ, Chen ST. Etiologic study of young ischemic stroke in Taiwan. Stroke. 2002 Aug 1;33(8):1950-5.

16. Razzaq AA, Khan BA, Baig SM. Ischemic stroke in young adults of South Asia. JPMA. The Journal of the Pakistan Medical Association. 2002 Sep;52(9):417-22

17. Mehndiratta MM, Agarwal P, Sen K, Sharma B. Stroke in young adults: a study from a university hospital in north India. Medical Science Monitor. 2004 Sep 1;10(9):CR535-41.

18. US Department of Agriculture; US Department of Health and Human Services. Appendix Alcohol. Available at: http://health.gov/dietaryguidelines/2010/guidelines/ap pendix-9. Accessed Apr 18, 2010

19. https://www.cdc.gov/nchs/nhis/tobacco/tobacco_glossary. htm accessed on 10 Apr 2010.

20. Chobanian AV, Bakris GL, Black HR, Cushman WC, Green LA, Izzo, Jr JL, Jones DW, Materson BJ, Oparil S, Wright, Jr JT, Roccella EJ, and the National High Blood Pressure Education Program Coordinating Committee. The Seventh Report of the Joint National Committee on Prevention, Detection, Evaluation, and Treatment of High Blood PressureThe JNC 7

Report. JAMA. 2003;289(19):2560-71. doi:10.1001/jama.289.19.2560

21. Hjartåker A, Langseth H, Weiderpass E. Obesity and diabetes epidemics. InInnovative Endocrinology of Cancer 2008 (pp. 72-93). Springer New York

22. American Diabetes Association. (2010). Diagnosis and Classification of Diabetes Mellitus. Diabetes Care, 33, S62-S69.URL:

https://www.ncbi.nlm.nih.gov/pmc/articles/PMC2797383

23. World Health Organization 2006.

WHO health topics: anaemia. http://www.who.int/topics/anaemia/en/ [last accessed 10 Feb 2006]

24. McMullin MF. The classification and diagnosis of erythrocytosis. Int J Lab Hematol. 2008 Dec. 30(6):44759

25. Nencini P, Inzitari D, Baruffi MC, Fratiglioni L, Gagliardi R, Benvenuti L, Buccheri AM, Cecchi L, Passigli A, Rosselli A. Incidence of stroke in young adults in Florence, Italy. Stroke. 1988 Aug 1;19(8):97781.

26. Bevan H, Sharma K, Bradley W. Stroke in young adults. Stroke. 1990 Mar 1;21(3):382-6.

27. Pillai LV, Ambike DP, Nirhale S, Husainy SM, Pataskar S. Cerebral venous thrombosis: An experience with anticoagulation with low molecular weight heparin. Indian journal of critical care medicine. 2005 Jan 1;9(1):14.

28. Nayak SD, Nair M, Radhakrishnan K, Sarma PS. Ischaemic stroke in the young adult: clinical features, risk factors and outcome. The National medical journal of India. 1997;10(3):107-12.

29. Lipska K, Sylaja PN, Sarma PS, Thankappan Kr, Kutty VR, Vasan RS, Et al. risk factors for acute ischemic stroke in young adults in South India. J Neurol Neurosurg Psychiatry 2007;78:959-63.

30. Nedeltchev K, der Maur TA, Georgiadis D, Arnold M, Caso V, Mattle HP, Schroth G, Remonda L, Sturzenegger $\mathrm{M}$, Fischer U, Baumgartner RW. Ischaemic stroke in young adults: predictors of outcome and recurrence. Journal of Neurology, Neurosurgery \& Psychiatry. 2005 Feb 1;76(2):191-5. 
31. Bhat VM, Cole JW, Sorkin JD, Wozniak MA, Malarcher AM, Giles WH, Stern BJ, Kittner SJ. Dose-response relationship between cigarette smoking and risk of ischemic stroke in young women. Stroke. 2008 Sep 1;39(9):2439-43

32. Sridharan R. Risk factors for ischemic stroke: a case control analysis. Neuroepidemiology. 1992;11(1):24-30.

33. Samiullah S, Humaira M, Hanif G, Ghouri AA, Shaikh K. Etiological patterns of stroke in young patients at a tertiary care hospital. JPMA. The Journal of the Pakistan Medical Association. 2010 Mar;60(3):201-4.

34. Siddiqui FM, Kamal AK. Incidence and epidemiology of cerebral venous thrombosis. JPMA. The Journal of the Pakistan Medical Association. 2006;56(11):485. 